AperTO - Archivio Istituzionale Open Access dell'Università di Torino

\title{
Organically modified clays as binders of fumonisins in feedstocks
}

\section{This is the author's manuscript}

Original Citation:

Availability:

This version is available http://hdl.handle.net/2318/136115

since

Published version:

DOI:10.1080/03601234.2013.780941

Terms of use:

Open Access

Anyone can freely access the full text of works made available as "Open Access". Works made available under a Creative Commons license can be used according to the terms and conditions of said license. Use of all other works requires consent of the right holder (author or publisher) if not exempted from copyright protection by the applicable law. 


\section{(2) \\ UNIVERSITÀ DEGLI STUDI DI TORINO}

This is an author version of the contribution published on:

Questa è la versione dell'autore dell'opera:

Journal of Environmental Science and Health, part B, 48, 2013,http://dx.doi.org/10.1080/03601234.2013.780941

The definitive version is available at:

La versione definitiva è disponibile alla URL:

http://www.tandfonline.com/loi/lesb20 
Organically modified clays as binders of fumonisins in feedstocks.

\author{
ANDREA BAGLIERI ${ }^{1}$, AMEDEO REYNERI ${ }^{2}$, MARA GENNARI ${ }^{1}$, MICHELE NEGRE*² \\ ${ }^{1}$ Dipartimento di Scienze delle Produzioni Agrarie e Alimentari, Università di Catania, Via S. Sofia \\ 98, 95123 Catania, Italy \\ 2 Dipartimento di Scienze Agrarie, Forestali e Alimentari, Via Leonardo da Vinci 44, 10095 \\ Grugliasco, Italy
}

Corresponding author: Prof. Michèle Negre

e-mail: michele.negre@unito.it

Tel: + $0116708508 ;$ Fax: + 0116708692 


\begin{abstract}
The most promising and economical approach for detoxifying mycotoxins contaminated feedstuffs is the addition of nutritionally inert mineral adsorbents to animals diets to decrease the bioavailability of the mycotoxins during absorption in the gastrointestinal tract thus preventing uptake into the blood and subsequent distribution to organs. Many adsorbents, mainly activated carbon and clay minerals exhibit a high ability to bind most of the mycotoxins. On the other hand, adsorbents for fumonisins have been tested in only a few cases, though these mycotoxins are toxic to number of animal species. This study reports an investigation on the ability of organically modified clays to bind fumonisins $\mathrm{B}_{1}\left(\mathrm{FB}_{1}\right)$ and $\mathrm{B}_{2}\left(\mathrm{FB}_{2}\right)$. Organically modified clays are commercial materials prepared from natural clays, generally montmorillonite, by exchanging the inorganic cation with an ammonium organic cation. A screening experiment conducted on 13 organically modified clays and 3 non modified clays, used as controls, has confirmed that the presence of an organic cation in the clay interlayer promoted the adsorption of both fumonisins. On the basis of the results of the screening test, four modified clays and a Na-montmorillonite were selected for the determination of the adsorption kinetics and isotherms. On all the tested materials adsorption took place within one hour contact with fumonisins solutions. Adsorption isotherms have pointed out that the modified clays exhibited a higher adsorptive capacity than the unmodified clay. It was also demonstrated that, notwithstanding the reduced structural difference between $\mathrm{FB}_{1}$ and $\mathrm{FB}_{2}$, they were differently adsorbed on the modified clays. Addition of $2 \%$ modified clays to contaminated maize allowed a reduction of more than $70 \%$ and $60 \%$ of the amount of $\mathrm{FB}_{1}$ and $\mathrm{FB}_{2}$ released in solution. Although in vivo experiments are required to confirm the effectiveness of the organically modified clays, these preliminary results suggest that these materials are promising as fumonisins binders.
\end{abstract}

Keywords: Mycotoxin binders, fumonisins $\mathrm{B}_{1}$ and $\mathrm{B}_{2}$, organically modified clays. 


\section{Introduction}

Mycotoxins are a relatively large, diverse group of naturally occurring, fungal toxins, many of which have been strongly implicated as chemical agents of toxic disease in humans and animals.

Mycotoxins cause illness in, and can be lethal to, domestic animals fed mouldy feedstuffs. The economic impact of lowered productivity, decreased weight gain, decreased feed efficiency, increased incidence of disease due to immune system suppression, subtle damage to vital body organs, and interference with reproduction is many times greater than that of immediate morbidity and lethality. ${ }^{[1]}$ As a result, the feed industry is currently focused on reducing mycotoxin levels in feed raw materials and finished feeds. ${ }^{[2]}$

Several strategies for reducing the concentration of mycotoxins in food and feed have been proposed, including physical, chemical, and biological methods. The most promising and economical approach for detoxifying feedstuffs is the addition of nutritionally inert mineral adsorbents to animals diets to decrease the bioavailability of the mycotoxins during absorption in the gastrointestinal tract thus preventing uptake into the blood and subsequent distribution to organs. ${ }^{[3,4]}$ They can be recommended when all the prevention rules fail and, consequently, farmers suspect that feed has been contaminated with mycotoxins. ${ }^{[5]}$

Of the mycotoxins found in feedstocks, considerable attention has been given to fumonisins because on one hand they are the most diffuse toxins in farm feedstuff; on the other hand they cause leukoencephalomalacia (LEM) in horses and pulmonary oedema in pigs. LEM has been reported in many countries including the USA, Argentina, Brazil, Egypt, South Africa and China. Fumonisins are also toxic to the central nervous system, liver, pancreas, kidney and lungs in a number of animal species. ${ }^{[6]}$

Fumonisins $\mathrm{B}_{1}\left(\mathrm{FB}_{1}\right)$ and $\mathrm{B}_{2}\left(\mathrm{FB}_{2}\right)$ are metabolites of Fusarium proliferatum and Fusarium verticillioides having a long-chain hydrocarbon unit (similar to that of sphingosine and sphinganine) which plays a role in their toxicity. ${ }^{[7]} \mathrm{FB}_{2}$ has also been recently detected in Aspergillus niger. ${ }^{[8,9]}$ 
In vitro and in vivo experiments related to the ability of different adsorbents, mainly activated charcoal, aluminosilicates (zeolites, hydrated sodium calcium aluminosilicates (HSCAS) and clays) to bind mycotoxins, ${ }^{[1,3,10-12]}$ have been reported in a number of reviews. However, most of these studies concern aflatoxins, zearalenone and deoxinivalenol, adsorbents for fumonisins having been tested in only a few cases. Avantaggiato et al. ${ }^{[3]}$ report that activated charcoal and chlorestamine showed promising results by binding more than $90 \%$ of $\mathrm{FB}_{1}$. On the other hand, in vivo experiments conducted on rats ${ }^{[3,13]}$ and weanling piglets ${ }^{[14]}$ indicated that activated carbon was not effective in protecting against the effects of fumonisin consumption. Promising results in binding $\mathrm{FB}_{1}$ were obtained using organically modified adsorbents such as organozeolites ${ }^{[15]}$, which had previously been successfully tested for the binding of aflatoxin $\mathrm{B}_{1}$, zearalenone, ochratoxin $\mathrm{A}$ and the ergopeptine alkaloids. ${ }^{[4,16,17]}$

Modified clays or organoclays are prepared from natural clays, generally montmorillonite, by exchanging the inorganic cation with an ammonium organic cation. Modified clays are also effective sorbents for a variety of organic and inorganic contaminants. ${ }^{[18,19]}$ The hydrophobic character of the organically modified clays suggests that these materials could be useful in binding mycotoxins and they were successfully tested in vitro as sorbents of zearalenone. ${ }^{[20]}$ A concern about the use of organically modified clays as feed additives could be their possible toxicity because the cationic surfactants included in the clay structure are known to be toxic for microorganisms. Although organoclays are commercially available for a variety of applications, such as the production of nano-sized materials, only few studies have been conducted on their toxicity. Han et al., ${ }^{[21]}$ working on cells from different organs concluded that the toxicity of two organoclays on the viability and membrane damage was not severe. Contrasting results were obtained by Lordan et al. ${ }^{[22]}$ in experiments aimed to assess the cytotoxicity of a montmorillonite and an organically modified clay by measuring liver cells function and membrane integrity. Both materials were cytotoxic but the montmorillonite gave a worse performance than the modified clay in two of the three parameters attesting the cytotoxicity. This result indicates that the organoclay 
should be less toxic than montmorillonite, therefore less toxic than a compound largely used as human and animal dietary supplement without any mentioned negative effect. Consequently, although further investigation should be useful, there is no evidence of the toxicity of the organoclays. This is probably because the organic cation is not released when included in the clay structure.

The scope of this work was to assess the ability of some commercial organically modified clays to bind fumonisin $\mathrm{B}_{1}$ and $\mathrm{B}_{2}$, starting from naturally contaminated maize, and to compare the performance of these materials with that of unmodified clays.

\section{Materials and methods}

Modified clays.

The tested clays were natural $\mathrm{Na}$ montmorillonites in which the inorganic cation had been exchanged with an ammonium organic cation. Unmodified Na clays, Cloisite $\mathrm{Na}$ and Dellite LVF and a Na fluorotetrasilisic mica synthetic were used as controls. Cloisite Na, 10 A, 15 A, 20 A, 30 B, 93 A, were obtained from Southern Clay Products, Widnes, UK. Dellite LVF, 67G, 43 B, and 72 were from obtained from Laviosa, Livorno, Italy. Nanofil 2, 5, 9, 3000, and 3010 were obtained from Süd Chemie, Novara, Italy. Somasif MEE and MEE 100 were obtained from Unicoop, Tokyo, Japan. The properties of the tested materials, when available from the technical sheet, are reported in table 1 .

\section{Chemicals.}

All reagents were analytical or LC-MS grade. Fumonisin standard solutions purchased from SigmaAldrich (Milano, Italy) were used to calibrate the LC-MS/MS system.

Preparation of fumonisin aqueous solutions. 
For the adsorption studies described below, it was decided to extract fumonisin solutions from contaminated maize rather than use pure standard solutions, in order to take into consideration the possible influence that other components of the maize could have on the interaction. Solutions of $\mathrm{FB}_{1}$ and $\mathrm{FB}_{2}$ were obtained by extracting $50 \mathrm{~g}$ of naturally contaminated maize grains with $100 \mathrm{ml}$ water by mechanical shaking for 2 hours. The liquid phase was separated by filtration through a Whatman $\mathrm{N}^{\circ} 4$ filter. The concentration of the solution was determined after purification using immunoaffinity columns and LC-MS/MS analysis under the conditions indicated below. Solutions of $\mathrm{FB}_{1}$ and $\mathrm{FB}_{2}$ at the required concentrations were prepared by diluting with water.

Screening of the adsorptive capacity of the modified clays.

Four $\mathrm{ml}$ fumonisin solutions prepared from contaminated maize as described above and containing $1.8 \mathrm{mg} \mathrm{L}^{-1} \mathrm{FB}_{1}$ and $0.8 \mathrm{mg} \mathrm{L}^{-1} \mathrm{FB}_{2}$ were equilibrated, by mechanical shaking with $0.2 \mathrm{~g}$ clay for 24 hours. After separating the phases by centrifugation (10 min, $3000 \mathrm{rpm})$, the supernatant was purified using an immunoaffinity column and analysed by LC-MS/MS under the conditions described below. The amount of bound mycotoxin was calculated as the difference between the initial and the final concentration in the solutions

\section{Adsorption kinetics.}

The kinetics of adsorption were determined following equilibration of $0.2 \mathrm{~g}$ modified clay and $4 \mathrm{ml}$ fumonisins solutions ( $7.5 \mathrm{mg} \mathrm{Kg}^{-1} \mathrm{FB}_{1}, 4.8 \mathrm{mg} \mathrm{Kg}^{-1} \mathrm{FB}_{2}$ ), by mechanical shaking for 1, 2 5, 8 and 24 hours. The supernatant was separated by centrifugation (10 min, $3000 \mathrm{rpm})$ and analysed to determine the concentration of fumonisins under the conditions described above.

\section{Adsorption isotherms.}

Adsorption isotherms were obtained following equilibration of $0.2 \mathrm{~g}$ modified clay and $4 \mathrm{ml}$ fumonisin solutions at different concentrations (from 8.3 to $1.0 \mathrm{mg} \mathrm{L}^{-1} \mathrm{FB}_{1}$, from 6.9 to $0.5 \mathrm{mg} \mathrm{L}^{-1}$ 
$\mathrm{FB}_{2}$ ). The supernatant was separated by centrifugation (10 min, $\left.3000 \mathrm{rpm}\right)$ and analysed to determine the concentration of fumonisins under the conditions described below.

Binding of fumonisins by adding modified clays to contaminated maize.

Fifty g samples of contaminated maize ( $6.9 \mathrm{mg} \mathrm{Kg}^{-1} \mathrm{FB}_{1}$ and $1.8 \mathrm{mg} \mathrm{Kg}^{-1} \mathrm{FB}_{2}$ ) and $0.25,0.5$ and $1.0 \mathrm{~g}$ modified clays were mixed mechanically in a reciprocating shaker for $24 \mathrm{~h}$. The mixture was then extracted for $2 \mathrm{~h}$ with $100 \mathrm{ml}$ water. The concentration of $\mathrm{FB}_{1}$ and $\mathrm{FB}_{2}$ in the liquid phase was measured under the conditions described below.

\section{Clean-up procedure.}

Fumonisin solutions resulting from the experiments described above were purified on immunoaffinity columns using the following procedure: $2 \mathrm{ml}$ solution was diluted with $8 \mathrm{ml}$ methanol and $40 \mathrm{ml}$ PBS (pH 7.4). Ten $\mathrm{ml}$ of the diluted solution were eluted on a Fumonitest immunoaffinity column (Vicam). The column was then eluted with $5 \mathrm{ml}$ PBS and $2 \mathrm{ml}$ methanol. The final fraction was collected for LC-MS/MS analysis.

LC-MS analysis.

LC-MS/MS analysis was performed using a Varian 310 triple quadrupole mass spectrometer (Varian, Italy) equipped with an electrospray ionization ESI source, a 212 LC pump and dedicated software. Separation was performed on a Pursuit $5 \mathrm{C}_{18}$ column $(3 \mu \mathrm{m}, 150 \mathrm{~mm} \times 2.0 \mathrm{~mm})($ Varian, Italy). The mobile phase consisted of water (A) and acetonitrile (B), both containing $0.1 \%(\mathrm{~V} / \mathrm{V})$ acetic acid delivered at a flow rate of $0.2 \mathrm{ml} \mathrm{min}^{-1}$. The gradient was $20 \% \mathrm{~B}$ for 2 min then from 20 $\%$ to $80 \% \mathrm{~B}$ in $8 \mathrm{~min}$.

Mass spectrometric analyses were performed in the positive-ion mode, the nebulising gas was $\mathrm{N}_{2}$ (20 psi), the drying gas was $\mathrm{N}_{2}\left(300^{\circ} \mathrm{C}, 25 \mathrm{psi}\right)$, the capillary voltage was $67 \mathrm{kV}$ and the collision gas was argon set at 1.8 mTorr. The respective ion transitions were as follows: for $\mathrm{FB}_{1} \mathrm{~m} / \mathrm{z} 722 \rightarrow$ 
334 (collision energy $36 \mathrm{~V}$ ) and $\mathrm{m} / \mathrm{z} 722 \rightarrow 552$ (collision energy $32 \mathrm{~V}$ ), for $\mathrm{FB}_{2} \mathrm{~m} / \mathrm{z} 706 \rightarrow 318$ (collision energy $38 \mathrm{~V}$ ) and $\mathrm{m} / \mathrm{z} 706 \rightarrow 336$ ( collision energy $36 \mathrm{~V}$ ).

\section{Statistical analysis.}

Analytical data were evaluated by one-way ANOVA $(\mathrm{P}<0.005)$ followed by the Tuckey test for Multiple Comparison Procedures.

\section{Results and discussion}

\section{Screening test.}

The percentages of adsorption of $\mathrm{FB}_{1}$ e $\mathrm{FB}_{2}$ on the tested materials are reported in table 1. The unmodified $\mathrm{Na}$ montmorillonite Cloisite $\mathrm{Na}$ adsorbed both the fumonisins at levels higher than 40 $\%$. This result confirms that clays are able to bind fumonisins as already attested for other

mycotoxins such as aflatoxins, ${ }^{[23-28]}$ zearalenone, ${ }^{[29,30]}$ and deoxynivalenol. ${ }^{[30]}$ On the other hand the Na montmorillonite Dellite LVF and the sodium fluorotetrasilisic mica synthetic Somasif MEE 100 adsorbed about $50 \%$ of $\mathrm{FB}_{2}$ but only 17.5 and 28.3, respectively, of $\mathrm{FB}_{1}$ despite having about the same CEC and interlayer spacing as Cloisite Na. The different ability of the three clays to bind $\mathrm{FB}_{1}$ could be attributed to other factors, for example particle size, as observed for the adsorption of aflatoxin on different clays. ${ }^{[24,25]}$

Most of the modified clays tested exhibited a higher adsorptive capacity than the unmodified clays, confirming that the presence of the organic cation improves the affinity of the clays for the fumonisins. The nature of the organic cation was not responsible for the differences between the modified clays as attested by the minor adsorptive capacity of Dellite $72 \mathrm{~T}$, especially for $\mathrm{FB}_{1}$, when compared to the other clays exchanged with the same cation. The least active clays were Dellite $72 \mathrm{~T}$ and SE 3010 and Somasif MEE, especially as far as $\mathrm{FB}_{1}$ was concerned. 
Of the modified clays exhibiting a high adsorption percentage, Dellite 67G, Dellite 43B, Cloisite 30B and Cloisite 93A were selected for further investigation because they represent four different cations.

\section{Adsorption kinetics.}

The percentage of $\mathrm{FB}_{1}$ and $\mathrm{FB}_{2}$ adsorbed on the $\mathrm{Na}$ montmorillonite and on the modified clays at different contact times is reported in tables 2 and 3. The data confirm that there is a higher adsorption of both fumonisins on the modified clays than on the montmorillonite. Most adsorption took place within the first hour and no significant increase was observed later except in the case of $\mathrm{FB}_{2}$ on Cloisite $\mathrm{Na}$ where adsorption increased slightly between 8 and 24 hours. The amount of $\mathrm{FB}_{1}$ adsorbed $24 \mathrm{~h}$ after contact ranged between $85 \%$ and $95 \%$. These values are slightly higher than those obtained from the screening experiment. This discrepancy could be due to the fact that the kinetics experiment was conducted at a higher $\mathrm{FB}_{1}$ concentration than the screening test $(7.5$ versus $1.8 \mathrm{mg} \mathrm{Kg}{ }^{-1}$ ) and suggests that the extent of adsorption increased as the concentration of the solution increased. $\mathrm{FB}_{2}$ was slightly less adsorbed on the modified clays than $\mathrm{FB}_{1}(70-78 \%$ after $24 \mathrm{~h}$ contact), reflecting the results of the screening test. Adsorption of $\mathrm{FB}_{2}$ on Dellite $67 \mathrm{G}$ tended to be slightly lower than on the other modified clays but no significant differences were found after 24h.

\section{Adsorption isotherms.}

The adsorption isotherms of $\mathrm{FB}_{1}$ and $\mathrm{FB}_{2}$ on the modified and unmodified clays are illustrated in figure 1. The coefficients $\mathrm{K}_{\mathrm{f}}$ and $1 / \mathrm{n}$ of the Freundlich equation for each isotherm are reported in table 4. The adsorption isotherm of $\mathrm{FB}_{1}$ on Cloisite $\mathrm{Na}$ was C-type $(1 / \mathrm{n}=1)$, indicating that the amount adsorbed increased linearly to the increase in solution concentration. This agrees with the results of Aly et al. ${ }^{[31]}$ showing that the percentage of removing of $\mathrm{FB}_{1}$ from an aqueous solution by an Egyptian montmorillonite was nearly not affected by the fumonisin concentration. In contrast, 
$\mathrm{FB}_{1}$ adsorption isotherms on activated carbon and on several commercial feed additives indicated that the binding was a saturable process. ${ }^{[3]}$ The $\mathrm{FB}_{2}$ adsorption isotherm on Cloisite Na was L-type $(1 / \mathrm{n}<1)$, indicating a progressive saturation of the adsorption sites as the concentration of the mycotoxin increased. Although $\mathrm{FB}_{2}$ is usually found in feeds, it has been much less studied, probably because is less concentrated compare to $\mathrm{FB}_{1}$ in naturally contaminated feedstuff, and no adsorption isotherms are reported in the literature to compare with our results.

$\mathrm{FB}_{1}$ and $\mathrm{FB}_{2}$ are high molecular weight molecules formed by a 20-carbon aliphatic chain with an amino group at one end of the chain and two ester-linked tricarballylic acids at the other branched ends. No report concerning the pKs of fumonisins has been found in the literature. On the other hand, the pKa values for tricarballylic acid are $3.49,4.56$, and $5.83^{[32]}$ and the aliphatic amine group would be expected to have a pKa greater than 9. Consequently, the fumonisin molecules will be a zwitterion at $\mathrm{pHs}$ between 6 and 9, that is, at the $\mathrm{pH}$ value (close to 7) of the clay suspension. This implies that the molecule is probably bound to the clay adsorption sites through electrostatic interactions. A molecular dynamics simulation on $\mathrm{FB}_{1}$ indicates that the molecule in aqueous solution exhibits a relatively extended structure, ${ }^{[33]}$ therefore it could penetrate the clay interlayer. However, this type of interaction does not explain the different behaviour of the two fumonisins. $\mathrm{FB}_{2}$ varies structurally from $\mathrm{FB}_{1}$ with the absence of the hydroxyl group at $\mathrm{C}-10$. It is slightly less polar than $\mathrm{FB}_{1}$ but it is not clear why this difference affects its interaction with the clay.

Adsorption isotherms on the modified clays confirm that the fumonisins behave differently: the adsorption curves of $\mathrm{FB}_{2}$ were well fitted to the Freundlich equation as attested by the $\mathrm{R}^{2}$ values > 0.9 (table 4). On the basis of the shape of the isotherms and the Freundlich coefficients the nature of the modified cation did not affect the mechanism and the extent of adsorption. All the isotherms were S-type $(1 / \mathrm{n}>1)$, indicating that the adsorbed molecules promote adsorption through adsorbate-adsorbate interactions. The fact that results are not influenced by the type of cation suggests an unspecific adsorption promoted by the affinity of the long aliphatic chain of the fumonisin molecule with the $\mathrm{C}_{12}$ to $\mathrm{C}_{18}$ moieties of the hydrogenated tallow. Adsorption isotherms 
of $\mathrm{FB}_{1}$ on the modified clays were poorly described by the Freundlich equation as attested by the $\mathrm{R}^{2}$ values $<0.9$. These isotherms displayed an $\mathrm{S}$-shape as observed by Lemke et al. ${ }^{[20]}$ in the case of adsorption of zearalenone on organically modified montmorillonite. This behaviour was associated to specific adsorption sites. The $1 / \mathrm{n}$ and $\mathrm{Kf}$ adsorption values of $\mathrm{FB}_{1}$ on Cloisite $93 \mathrm{~A}$, Dellite 43A and Dellite 67G were not significantly different (95\% confidence) while Cloisite 30B adsorbed lower amounts of $\mathrm{FB}_{1}$ than the other modified clays. The modifying cation of Cloisite $30 \mathrm{~B}$ is more polar than that of the other clays because of the two hydroxyethyl groups. The minor adsorption of $\mathrm{FB}_{1}$ when compared with the other clays agrees with the results of Lemke et al. ${ }^{[20]}$ indicating that adsorption of zearalenone on organoclays increased as the hydrophobicity of the exchanged cation increased. Although $\mathrm{FB}_{1}$ is a more polar and larger molecule than zearalenone it seems that its adsorption is also promoted by the presence of the long aliphatic chains of the hydrogenated tallow. Adsorption isotherms have indicated that $\mathrm{FB}_{1}$ and $\mathrm{FB}_{2}$ behave differently notwithstanding the similarity of their chemical structure. $\mathrm{FB}_{2}$ has been much less studied than $\mathrm{FB}_{1}$ but it has been seen to be more cytotoxic. ${ }^{[34]}$ This suggests that more studies regarding $\mathrm{FB}_{2}$ would be useful.

\section{Binding of fumonisins by addition of modified clays to contaminated maize.}

Figure 2 reports the percentage of fumonisins released by water extraction from naturally contaminated maize previously mixed mechanically with different amounts of clay. The addition of 0.5 and $1 \%$ of Cloisite $\mathrm{Na}$ and of the four modified clays released more than $70 \%$ of the fumonisins in solution, therefore, at these concentrations, the sorbents were not effective as fumonisin binders. The addition of $2 \%$ Cloisite Na did not improve the performance of this material, while the modified clays allowed less than $30 \% \mathrm{FB}_{1}$ and less than $40 \% \mathrm{FB}_{2}$ to be released in solution. The minor capacity to adsorb $\mathrm{FB}_{2}$ as compared to $\mathrm{FB}_{1}$ reflects the results indicated by the screening test and the adsorption isotherms. On the other hand, considering that in contaminated cereals, the concentration of $\mathrm{FB}_{2}$ is usually about $1 / 3$ that of $\mathrm{FB}_{1},{ }^{[2]}$ the minor efficacy 
of the clays to capture $\mathrm{FB}_{2}$ should not be a problem in terms of the final concentration of this fumonisin.

\section{Conclusions}

The study has indicated that the organically modified clays exhibited a much higher adsorptive capacity for both fumonisins $\mathrm{B}_{1}$ and $\mathrm{B}_{2}$ in aqueous solution than a montmorillonite which is a typical material used as mycotoxin binder. Moreover, when added to contaminated maize, the montmorillonite was not active while $2 \%$ addition of some organically modified clays allowed to reduce more than $70 \%$ and $60 \%$ of the amount of $\mathrm{FB}_{1}$ and $\mathrm{FB}_{2}$ released in solution. It was also demonstrated that, notwithstanding the reduced structural difference between $\mathrm{FB}_{1}$ and $\mathrm{FB}_{2}$, they were differently adsorbed on the modified clays.

The preliminary experiment conducted on the $2 \%$ addition of some organically modified clays to the contaminated maize was promising but should be confirmed by further studies attesting that i) the materials maintain their adsorptive capacity in the conditions of gastrointestinal tract, ii) they do not have any negative effect as for example the binding of nutrients and vitamins, iii) they are effective in vivo.

\section{Acknowledgements}

The authors wish to thank Chiara Gabriolotto and Daniela Vindrola for running the experimental part. This study has been performed with financial support of Regione Piemonte (CIPE 2006 Master Plan for the production of cereals for the food chain with low mycotoxin contamination) and of University of Turin (ex-60\%).

\section{References}

[1] Huwig, A.; Freimund, S.; Käppeli, O.; Dutler, H. Mycotoxin detoxication of animal feed by different adsorbents. Toxicol. Lett. 2001, 122, 179-188. 
[2] Monbaliu, S.; van Poucke, C.; Detavernier, C.; Dumoulin, F.; van del Velde, M.; Schoeters, E.; van Dyck, S.; Averkieva, O.; van Peteghem, C.; De Saeger S. Occurrence of mycotoxins in feeds as analysed by a multi-mycotoxin LC-MS/MS method. J. Agric. Food Chem. 2010, 58, 66-71.

[3] Avantaggio, G.; Solfrizzo, M.; Visconti, A. Recent advances on the use of adsorbent materials for detoxification of Fusarium mycotoxins. Food Addit. Contam. 2005, 22, $379-388$.

[4] Daković, A.; Matijašević, S.; Rottinghaus, G. E.; Dondur, V.; Pietrass, T.; Clewett, C.F.M. Adsorption of zearalenone by organomodified natural zeolitic tuff. J. Colloid Interface Sci. 2007, 311, 8-13.

[5] Jouany, J.P. Methods for preventing, decontaminating and minimizing the toxicity of mycotoxins in feeds. Anim. Feed Sci. Technol. 2007, 137, 342-362.

[6] FAO Food and Nutrition. Paper 73. 2001. Manual on the application of the HACCP system in mycotoxin prevention and control. ftp://ftp.fao.org/docrep/fao/005/y1390e/y1390e00.pdf

[7] Zain, M.E. Impact of mycotoxins on humans and animals. J. Saudi Chem. Soc. 2011, 15, $129-144$.

[8] Frisvad, J.C.; Smedsgaard, J.; Samson, R.A.; Larsen, T.O.; Thrane, U. Fumonisin B2 production by Aspergillus niger. J. Agric. Food Chem. 2007, 55, 9725-9732.

[9] Mogensen, J.M.; Frisvad, J.C.; Thrane, U.; Nielsen, K.F. Production of fumonisin B $_{2}$ by Aspergillus niger on grapes and raisins. . J. Agric. Food Chem. 2010, 58, 954-958.

[10] Kabak, B.; Dobson, A.D.W.; Var, I. Strategies to prevent mycotoxin contamination of food and animal feed: a review. Crit. Rev. Food Sci. Nutr. 2006, 46, 593-619.

[11] Jard, G.; Liboz, T.; Mathieu, F.; Guyonvarch, A.; Lebrihi, A. Review of mycotoxin reduction in food and feed: from prevention in the field to detoxification by adsorption or transformation. Food Addit. Contam. 2011, 28, 1590-1609. 
[12] Kolosowa, A.; Stroka, J. Substances for reduction of the contamination of feed by mycotoxins: a review. World Mycotoxin J. 2011, 4, 225-256.

[13] Solfrizzo, M.; Carratu, M.R; Avantaggiato, G.; Galvano, F.; Pietri, A.; Visconti, A. Ineffectiveness of activated carbon in reducing the alteration of sphingolipid metabolism in rats exposed to fumonisin-contaminated diet. Food Chem. Toxicol. 2001, 39, 507-511.

[14] Piva, A.; Casadei, G.; Pagliuca, G.; Cabassi, E.; Galvano, F.; Solfrizzo, M.; Riley, R.T.; Diaz, D.E. Activated carbon does not prevent the toxicity of culture material containing fumonisin $\mathrm{B}_{1}$ when fed to weanling piglets. J Anim. Sci. 2005, 83, 1939-1947.

[15] Daković, A; Tomašević-Canović, M.; Rottinghaus, G.; Matijašević, S.; Sekulić, Z. Fumonisin $\mathrm{B}_{1}$ adsorption to octadecyldimethylbenzyl ammonium-modified clinoptilolite-rich zeolitic tuff. Micropor. Mesopor. Mat. 2007, 105,285-290.

[16] Tomašević-Canović, M.; Daković, A; Rottinghaus, G. ; Matijašević, S.; Duričić, M. Surfactant modified zeolites-new efficient adsorbent for mycotoxins. Micropor. Mesopor. Mat. 2003, 61, 173-180.

[17] Daković, A.; Tomašević-Canović, M.; Dondur, V.; Rottinghaus, G. E.; Medaković, V.; Zarić, S. Adsorption of mycotoxins by organozeolites. Colloids Surf. B Biointerface, 2005, 46, 20-25.

[18] Ake, C. L.; Wiles, M. C.; Huebner, H. J.; McDonald, T. J.; Cosgriff, D.; Richardson, M. B.; Donnelly, K. C.; Phillips, T. D. Porous organoclay composite for the sorption of polycyclic aromatic hydrocarbons and pentachlorophenol from groundwater. Chemosphere, 2003, 835-844.

[19] Baglieri, A.; Borzi, D.; Negre, M.; Abbate, C.; Gennari, M. Removal of fenhexamid and pyrimethanil from aqueous solutions by clays and organoclays. J. Environ. Sci. Health. Part B. 2009, 44, 220-225.

[20] Lemke, S. L.; Grant, P. G.; Phillips, T. D. Adsorption of zearalenone by organophilic montmorillonite clay. J. Agric. Food Chem. 1998, 46, 3789-3796. 
[21] Han, H.; Lee, Y.; Lee, M.; Patil, A.J.; Shin, H. Magnesium and calcium organophyllosilicates: synthesis and in vitro cytotoxicity study. Appl. Mater. Interfaces. 2011, 3, 2564-2572.

[22] Lordan, S.; Kennedy, J.E.; Higginbotham, C.L. Cytotoxic effects induced by unmodified and organically modified nanoclays in the human hepatic HepG2 cell line. $J$. Applied Toxicol. 2011, 31, 27-35

[23] Afriyie-Gyawu, E.; MacKie, J.; Dash, B.; Wiles, M.; Taylor, J.; Huebner, H.; Tang, L.; Guan, H.; Wang, J. S.; Phillips, T. Chronic toxicological evaluation of dietary NovaSil clay in Sprague-Dawley rats. Food Addit. Contam. 2005, 22, 259-269.

[24] Dixon, J.B.; Kannewischer, M. G.; Tenerio Arvide, M. G.; Barrientos Velazquez, A. L. Aflatoxin sequestration in animal feeds by quality-labeled smectite clays: An introductory plan. Appl. Clay Sci .2008, 40, 201-208.

[25] Mulder, I.; Barrientos Velazquez, L.; Tenorio Arvide, G.; White, G.N.; Dixon, J. B. Smectite clay sequestration of aflatoxin B1: Particle size and morphology. Clays Clay Min. 2008, 56, 558-570.

[26] Phillips, T. D.; Afriyie-Gyawu, J.; Williams, J.; Huebner, H.; Ankrah, N. A.; OforiAdjel, D.; Jolly, P.; Johnson, N.; Taylor, A.; Marroquin-Cardona, A.; Xu, L.; Tang, L.; Wang, J. S. Reducing human exposure to aflatoxin through the use of clay: A review. Food Addit. Contam. 2008, 25, 134-145.

[27] Marroquin-Cardona, A.; Deng, Y.; Taylor, J. F.; Hallmark, C. T.; Johnson, N. M.; Phillips, T. D. In vitro and in vivo characterization of mycotoxin-binding additives used for animal feeds in Mexico. Food Addit. Contam. 2009, 26, 733-743.

[28] Deng, Y.; Barrientos-Velazquez, A. L.; Billes, F.; Dixon, J. B. Bonding mechanisms between aflatoxin B1 and smectite. Appl. Clay Sci. 2010, 50, 92-98.

[29] Abbes, S.; Ben Salah-Abbes, J.; Ouanes, Z.; Houas, Z.; Othman, O. ; Bacha, H.; Abdel-Wahhab, M. A.; Oueslati, R. Preventive role of phyllosilicate clay on the 
immunological and biochemical toxicity of zearalenone in balb/c mice. Int. Immunopharmacol. 2006, 6, 1251-1258.

[30] Sabater-Vilar, M.; Malekinejad, H.; Selman, M. H. J.; van der Doelen, M. A.; FinkGremmels, J. In vitro assessment of adsorbents aiming to prevent deoxynivalenol and zearalenone mycotoxicoses. Mycopathologia, 2007, 163, 81-90.

[31] Aly, S.E.; Abdel-Galil, M.M.; Abdel-Wahhab, M. A. Application of adsorbent agents technology in the removal of aflatoxin B1 and fumonisin B1 from malt extract. Food Chem. Toxicol. 2004, 42, 1825-1931.

[32] Greenstein, J.P. Studies of multivalent aminoacids and peptides. The synthesis of certain derivatives of lysylglutamic acid. J. Biol. Chem. 1935, 109, 541-544.

[33] Momany, F.A.; Dombrink-Kurtzman, M.A. Molecular Dynamics Simulations on the mycotoxin fumonisin $\mathrm{B}_{1}$. J. Agric. Food Chem. 2001, 49, 1056-1061.

[34] Gutleb, A.C.; Morrison, E.; Murk, A.J. Cytotoxicity assays for mycotoxins produced by Fusarium strains: a review. Environ. Toxicol. Phar. 2002, 11, 309-320. 


\section{Figure Captions}

Figure 1. Adsortion isotherms of $\mathrm{FB}_{1}(\boldsymbol{\nabla})$ and $\mathrm{FB}_{2}(\mathbf{\square})$ on cloisite $\mathrm{Na}(\mathrm{A})$, cloisite $30 \mathrm{~B}(\mathrm{~B})$, cloisite 93A (C), dellite 43B (D) and dellite 67G ( E) .

Figure 2. Percentage of $\mathrm{FB}_{1}$ and $\mathrm{FB}_{2}$ released in solution from contaminated maize at different concentrations of cloisite $\mathrm{Na}$ and modified clays. 
Fig. 1
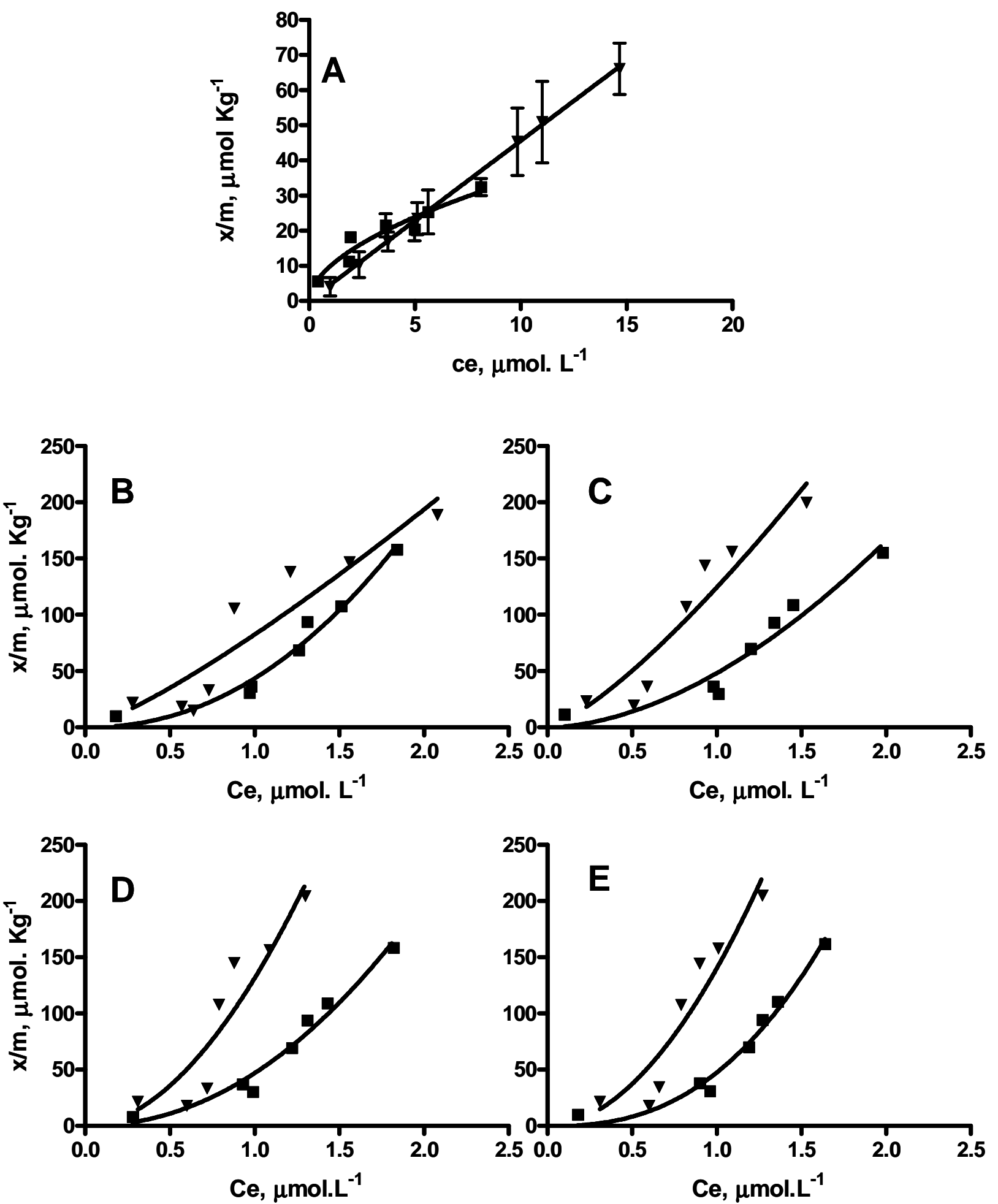
Fig. 2

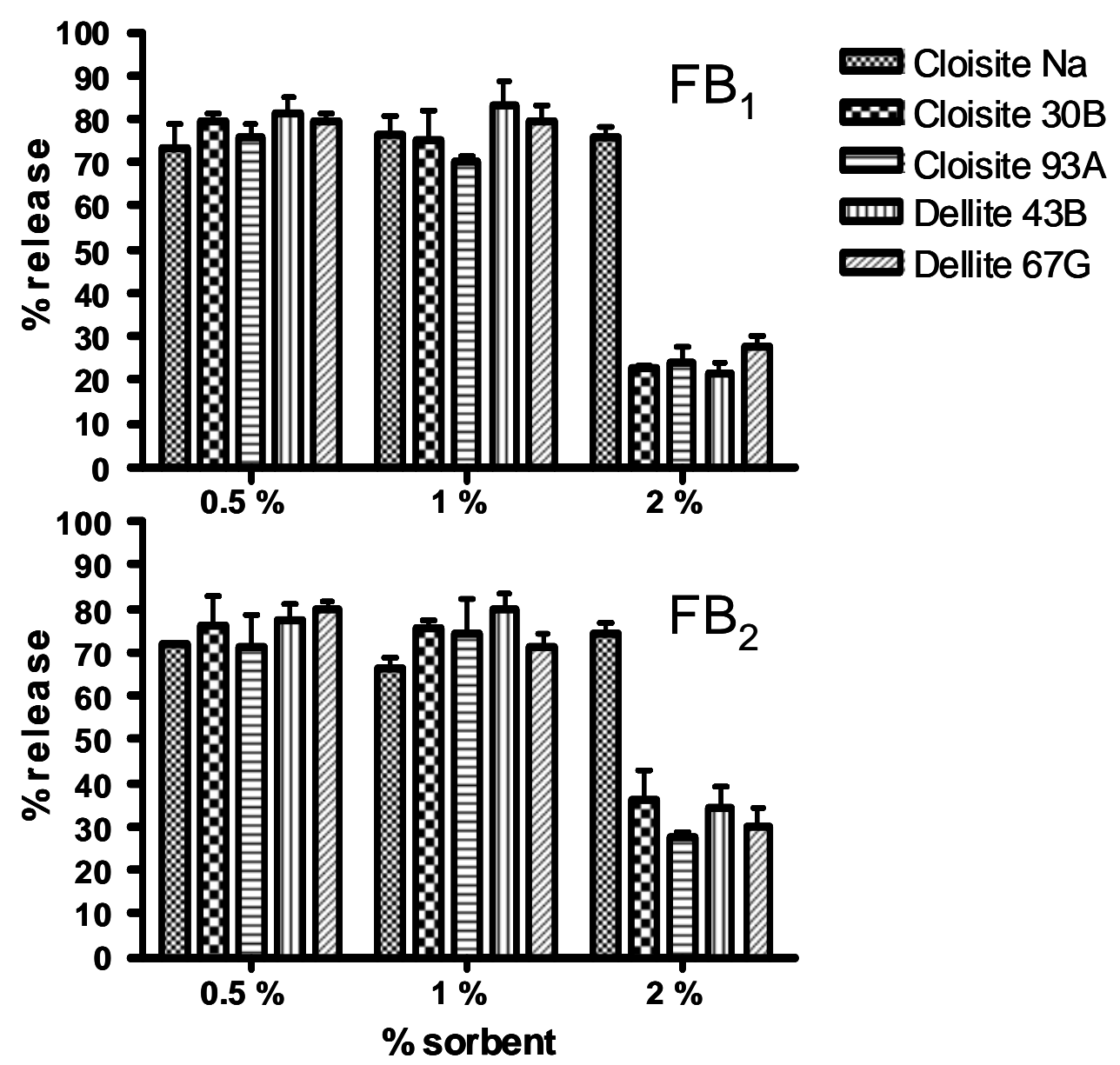


Table 1. Some properties of the modified clays and the percentage of adsorption of $\mathrm{FB}_{1}$ and $\mathrm{FB}_{2}$. (Hydrogenated tallow $=\mathrm{C}_{\mathrm{n}} \mathrm{H}_{(2 \mathrm{n}+1)},(\mathrm{n}=12-18)$

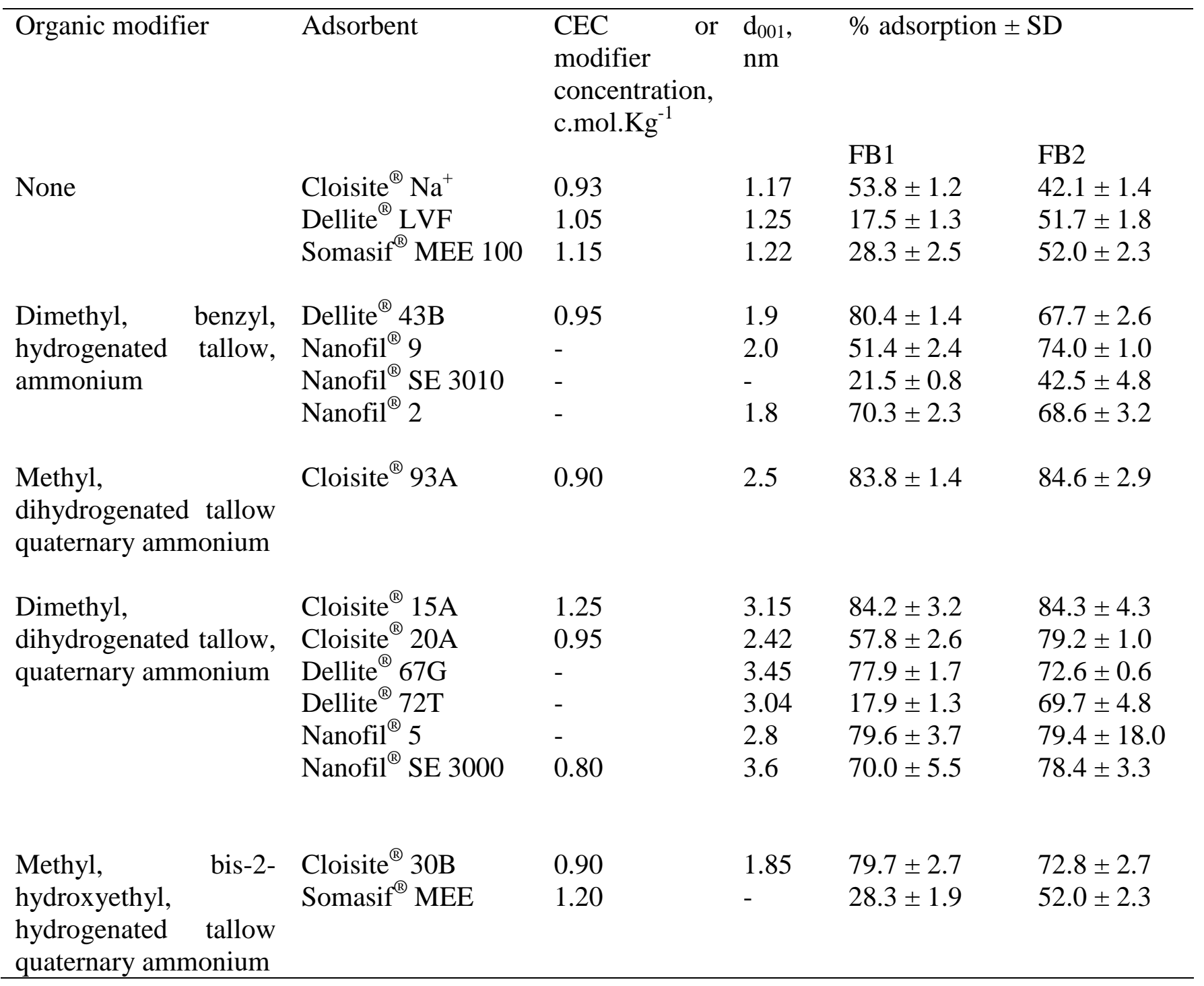


Table 2. Influence of the time of contact on the percentage of adsorbed $\mathrm{FB}_{1}$.

\begin{tabular}{llllll}
\hline Time, hours & Cloisite Na & Cloisite 30B & Cloisite 93A & Dellite 43B & Dellite 67G \\
1 & $43.8_{\mathrm{a}} \pm 4.80$ & $88.7_{\mathrm{b}} \pm 1.96$ & $88.8_{\mathrm{b}} \pm 1.79$ & $88.3_{\mathrm{b}} \pm 2.61$ & $89.4_{\mathrm{b}} \pm 0.96$ \\
2 & $40.1_{\mathrm{a}} \pm 5.04$ & $89.6_{\mathrm{b}} \pm 2.43$ & $91.3_{\mathrm{b}} \pm 1.34$ & $92.6_{\mathrm{b}} \pm 0.86$ & $92.3_{\mathrm{b}} \pm 1.21$ \\
5 & $31.0_{\mathrm{a}} \pm 4.82$ & $89.7_{\mathrm{b}} \pm 1.60$ & $91.3_{\mathrm{b}} \pm 1.15$ & $89.8_{\mathrm{b}} \pm 2.87$ & $91.0_{\mathrm{b}} \pm 2.01$ \\
8 & $35.2_{\mathrm{a}} \pm 8.90$ & $94.0_{\mathrm{b}} \pm 1.95$ & $89.8_{\mathrm{b}} \pm 0.58$ & $91.3_{\mathrm{b}} \pm 0.60$ & $89.6_{\mathrm{b}} \pm 1.34$ \\
24 & $43.9_{\mathrm{a}} \pm 4.99$ & $95.8_{\mathrm{b}} \pm 2.76$ & $87.8_{\mathrm{b}} \pm 2.04$ & $86.2_{\mathrm{b}} \pm 2.55$ & $85.9_{\mathrm{b}} \pm 3.60$ \\
\hline
\end{tabular}


Table 3. Influence of the time of contact on the percentage of adsorbed $\mathrm{FB}_{2}$.

\begin{tabular}{llllll}
\hline Time, hours & Cloisite Na & Cloisite 30B & Cloisite 93A & Dellite 43B & Dellite 67G \\
1 & $30.5_{\mathrm{a}} \pm 2.94$ & $74.2_{\mathrm{cd}} \pm 1.24$ & $77.7_{\mathrm{c}} \pm 1.28$ & $72.6_{\mathrm{cd}} \pm 6.72$ & $64.0_{\mathrm{d}} \pm 5.93$ \\
2 & $32.4_{\mathrm{a}} \pm 1.33$ & $79.2_{\mathrm{c}} \pm 1.25$ & $81.0_{\mathrm{c}} \pm 0.66$ & $76.0_{\mathrm{c}} \pm 5.71$ & $64.8_{\mathrm{d}} \pm 2.52$ \\
5 & $39.1_{\mathrm{a}} \pm 5.68$ & $74.8_{\mathrm{c}} \pm 5.40$ & $73.5_{\mathrm{cd}} \pm 5.61$ & $75.1_{\mathrm{c}} \pm 6.25$ & $59.9_{\mathrm{d}} \pm 2.42$ \\
8 & $38.0_{\mathrm{a}} \pm 3.82$ & $74.9_{\mathrm{c}} \pm 5.05$ & $75.6_{\mathrm{c}} \pm 5.43$ & $73.2_{\mathrm{c}} \pm 5.97$ & $59.2_{\mathrm{d}} \pm 1.91$ \\
24 & $51.8_{\mathrm{b}} \pm 5.77$ & $75.1_{\mathrm{cd}} \pm 2.74$ & $73.4_{\mathrm{cd}} \pm 3.43$ & $77.8_{\mathrm{cd}} \pm 4.63$ & $71.0_{\mathrm{d}} \pm 3.64$ \\
\hline
\end{tabular}


Table 4. Freundlich coefficients ( $\pm \mathrm{SD}$ ) of the adsorption isotherms of $\mathrm{FB}_{1}$ and $\mathrm{FB}_{2}$ on clays.

\begin{tabular}{lllllll}
\hline & $\mathrm{FB}_{1}$ & & & $\mathrm{FB}_{2}$ & & \\
& $\mathrm{Kf}$ & $1 / \mathrm{n}$ & $\mathrm{R}^{2}$ & $\mathrm{Kf}$ & $1 / \mathrm{n}$ & $\mathrm{R}^{2}$ \\
Cloisite Na & $4.6 \pm 0.09$ & $0.99 \pm 0.01$ & 0.9995 & $9.9 \pm 0.81$ & $0.55 \pm 0.05$ & 0.9162 \\
Cloisite 30B & $82.5 \pm 6.43$ & $1.23 \pm 0.13$ & 0.8591 & $43.5 \pm 2.47$ & $2.15 \pm 0.12$ & 0.9693 \\
Cloisite 93A & $124.3 \pm 5.96$ & $1.31 \pm 0.13$ & 0.8921 & $48.2 \pm 3.50$ & $1.78 \pm 0.14$ & 0.9332 \\
Dellite 43B & $131.4 \pm 7.28$ & $1.88 \pm 0.23$ & 0.8531 & $47.0 \pm 2.57$ & $2.09 \pm 0.12$ & 0.9670 \\
Dellite 67G & $140.1 \pm 6.55$ & $1.91 \pm 0.20$ & 0.8862 & $47.5 \pm 4.24$ & $2.53 \pm 0.23$ & 0.9781 \\
\hline
\end{tabular}

